\title{
De pueblo de indios a centro regional. Las transformaciones históricas de un municipio de Chiapas
}

\author{
Miguel LisBona GUILLÉN \\ Centro de Investigaciones y Estudios Superiores \\ en Antropología Social (CIESAS-Sureste)
}

Los estudios de comunidad realizados en Chiapas, durante varias décadas, crearon la impresión de poblaciones indígenas sin historia, instauradas en un tiempo que, por étnico, las convertía en espacios míticos: indígenas que conservaban su saber prehispánico, resistentes a cualquier cambio y guardianes de su cultura milenaria en medio de un mundo hostil modernizador, y de una cultura nacional encaminada a desbaratar cualquier atisbo de indianidad. Sin embargo, el análisis histórico nos vuelve a la realidad e interroga sobre cómo se imbricaron estas poblaciones en el entramado colonial, cómo se crearon nuevos asentamientos a partir de congregaciones religiosas y administrativas, y qué papel jugaron en el nuevo marco político resultante del México independiente. Estas y otras cuestiones forman parte de un trabajo más amplio que realizamos sobre un municipio chiapaneco, Tapilula; pero en el presente texto mostraremos brevemente cómo este pueblo de origen prehispánico y habitado por indígenas hablantes de zoque se ha transformado, en la actualidad, en un centro regional con escasos hablantes de lengua indígena. Igualmente, nos interrogamos sobre cómo la llegada de inmigrantes y las transformaciones económicas del lugar pueden leerse desde una perspectiva de frontera $\mathrm{o}$ construcción étnica.

Las malas impresiones que los conquistadores tuvieron al adentrarse en la región no parecían buenas cartas de recomendación para Tapilula y los pueblos vecinos. La vegetación abundante y los caminos enlodados prácticamente todo el año, por los altos índices de precipitación pluvial, representaban un obstáculo para el asentamiento de españoles. No es extraño entonces que, entrado el siglo xviII, en los pueblos de la Sierra Pantepec sólo aparecieran escasos habitantes definidos como blancos, y prácticamente ninguno considerado mestizo (Villa Rojas 1990: 33). Los colonizadores, pues, no tuvieron un peso específico expresado en asentamientos o fincas especializadas; más bien aprovecharon el tributo, los productos naturales como la grana cochinilla y los manufacturados, 
como las mantas, para acumular capital a costa de los indígenas zoques. Pero, sobre todo, se sirvieron de la mano de obra para llevar cargas en los desplazamientos comerciales.

No parece que a principios del siglo XIX se modificara el panorama en cuanto a presencia de población no indígena. El obispo Sanmartín afirma, en una visita parroquial al partido de los zoques, que en 1820 la misa ofrecida en Tapilula contó con la presencia de uun creciente número de feligreses yndios, única clase de que componen los habitantes de este citado pueblo" ${ }^{1}$. Otro ejemplo lo ofrecen los informes parroquiales de mediados del siglo XIX, que remiten a un crecimiento demográfico precario en Tapilula. El sacerdote consideraba que "debería tener un crecido número de habitantes, según lo antiguo de su fundación; pero su temperamento parece no muy bueno, y le saco causa de que solamente tenga ahora 325 [habitantes]. Estos comentarios se producían en los prolegómenos de la independencia mexicana, hecho que cambiaría lenta, pero definitivamente, la fisonomía del municipio. Las transformaciones económicas, las luchas por la tierra y la migración tienen en la actualidad no sólo un reflejo estadístico sino que son perceptibles al visitante. Los datos más recientes confirman la supremacía demográfica de Tapilula con respecto a los municipios vecinos (Ixhuatán, Pantepec, Rayón y Tapalapa), y su mayor índice de crecimiento.

Desde otra perspectiva, si hacemos caso de la lengua indígena hablada, Tapilula tiene una clara desventaja. Sólo un $10,9 \%$ de su población habla el idioma zoque, frente al $95,4 \%$ de Tapalapa o al 50,3\% de Pantepec. Con estas cifras del censo de 1990 se comprueba la transformación de un municipio históricamente zoque a otro donde la presencia del zoque, al menos en cuanto a idioma hablado, es sólo de una décima parte de su población total. Pero este panorama actual no puede entenderse sin hacer referencia a los aspectos históricos que conducen a esta supremacía de Tapilula con respecto a los municipios vecinos, así como su progresivo y acelerado abandono de la lengua indígena. Si hasta prácticamente el siglo XIX los colonizadores habían utilizado las regiones de Mezcalapa para la extracción de materias primas y de mano de obra para fines comerciales, desde mediados de dicho siglo las leyes y medidas liberalizadoras provocaron la creciente expansión y control de pobladores no indígenas sobre las antiguas tierras de indios y de la Iglesia ${ }^{2}$.

\footnotetext{
1 AHD, Asuntos Eclesiásticos II, B. 3, Visitas parroquiales.

2 Los territorios poco accesibles, y con predominio de población indígena, habían sido zonas de refugio para los que escapaban de la explotación de los encomen-
} 
El cura de Tapilula informaba en 1851, por ejemplo, de que sólo existía en el territorio perteneciente a la parroquia una hacienda, denominada "Sacualpa" ${ }^{3}$, a cinco leguas al norte de la cabecera de Tapilula, con una población aproximada de "40 almas" ${ }^{4}$. Pocos años después, en 1858, el sacerdote de la misma parroquia menciona la presencia de familias, posiblemente inmigrantes, que "procuran progresar" vendiendo aguardiente o dedicándose a la usura. Pero en la misma descripción señala ya la existencia de fincas, aunque no las menciona como tales, más bien se refiere a familias que cuentan con

\begin{abstract}
criados domésticos, los que pasado el tiempo de formar sementeras dedican a sus mosos a transportar cargas ya para Tabasco o ya para esa [¿San Cristóbal'?] Los amos reciben el flete, como ellos llaman, y el moso recibe de ellos 40 o 50 masorcas de maís, para que reducido a masa le sirva de alimento mientras dilata el viaje. Estas cosas, aunque tan malas en sí, y que se decea evitarlas, demuestran sin embargo que el pueblo especula y que camina a su civilización 5 .
\end{abstract}

Dos décadas después, en 1871, el cura advertía ya de la existencia de dos "haciendas" en su territorio, la mencionada anteriormente (Zacualpa) y "La Punta" en Ixhuatán ${ }^{6}$. Con respecto a esta última informa del ofrecimiento del "dueño [...] con todos sus mosos" para reparar las goteras y desperfectos de la iglesia del pueblo. La negativa de los pobladores estaba fundada en que "esa cooperación a quitada de goteras sería en perjuicio de todos los hijos del pueblo, porque con el tiempo se tomaba los terrenos del pueblo, en recompensa con el servicio que prestaría. Esta clara alusión a la confrontación entre los nuevos propietarios que estaban llegando al pueblo y los zoques de Ixhuatán, pueblo cercano a Tapilula, se certifica con la decisión de no reparar la iglesia y alevantar hermita en

deros. Pero progresivamente a partir de finales del siglo XVIII, estos territorios vieron la lenta pero penetrante llegada de poblaciones no indígenas, que se asentaban en las poblaciones como artesanos y comerciantes, o como rancheros a las orillas del municipio. En muchos casos las actividades comerciales estuvieron ligadas a la venta de aguardiente, elemento imprescindible en las celebraciones festivas (Wasserstrom 1992: 157).

3 La finca "Zacualpa" en el municipio de Solosuchiapa fue invadida tras el levantamiento armado zapatista, y comprada por el gobierno en 1994.

4 AHD, Correspondencia IV, D. 1, Tapilula. Informe de población del curato, 1851.

5 AHD, Asuntos Parroquiales IV, D. 1, Tapilula, 1858.

6 Como referencia a la existencia de los peones acasillados en Ixhuatán, Moisés T. de la Peña (1951: 175) hace mención de un barrio nuevo de peones liberados en 1914. 
el sementerio de la iglesia arruinada, en esta virtud espero sabias istrucciones, para desir a estos miserables lo que sea conveniente y más asertado sobre este particular", afirmaba el sacerdote ${ }^{7}$. En ese mismo sentido, la inserción de los indígenas zoques en el trabajo de las haciendas provocó la progresiva retirada de su labor como cargadores; en 1872 el cura Manuel Ascón se quejaba de "la gran escasez de cargadores que por cuya causa, aun los comerciantes que bajan y suben con la mira de solicitar cargadores de ambos pueblos, tienen que demorarse por lo menos quinse días por falta de conducto" 8 .

Las leyes federales y estatales propiciaron que la fiebre por ocupar tierras de indios siguiera vigente hasta principios del siglo $\mathrm{xx}$. Los zoques de Ixhuatán y Tapilula ya se habían defendido de dicha ofensiva al denunciar como privadas sus tierras comunales en 1878 (García de León 1989: I, 161), sin embargo poco pudieron hacer ya que entre 1894 y 1907 aparecen un sinnúmero de demandas para obtener tierras ${ }^{9}$. Es decir, a finales del siglo xix y principios del xx la fiebre expansionista sobre el desierto de Mezcalapa, como también fue nombrada la región, era constante y anunciaba una nueva forma de usar y distribuir la tierra, así como una entrada de población foránea a las comunidades zoques. Si la escasa población y la práctica ausencia de colonizadores fueron la característica regional dominante durante el régimen colonial, las transformaciones políticas del periodo independiente obligaron a las comunidades a defender sus tierras de muy distintas formas, una de ellas, por no decir la única con certidumbre legal, fue acudir a los cauces institucionales. Los campesinos de Tapilula explicaron el proceso contemporáneo que definió su territorio aprovechando una solicitud de dotación de tierras. Según esta descripción,

[...] desde el año de 1894, es decir ase 39 años este pueblo está en poseción quieta y pasífica de una superficie de 2.170 hectáreas de tierras, con el carácter de ejido, cuya superficie fue deslindada y fraccionada por orden del Gobierno del Estado en pequeñas posesiones ejidales que fueron adjudicadas en venta ${ }^{10}$.

7 AHD, Asuntos Parroquiales IV, D. 1, Tapilula, 1871.

8 AHD, Asuntos Parroquiales IV, D. 1, Tapilula, 1872.

9 AHE, Inventario Gral. de la Oficina General de Ejidos, Sección Fomento, III, Expedientes 12 y 31, 1908.

10 AECAM, Exp. 450, 29 de abril de 1933, instauración del expediente para la dotación de Ejido dirigida al gobernador Victorico R. Grajales. Con fecha 10 de mayo del mismo año se publicó la solicitud, efectuada el día 16 de abril en el Periódico Oficial del Gobierno del Estado de Chiapas, tomo L, n. ${ }^{\circ}$ 19: 5-6. 
Cuatro representantes de los campesinos tapilultecos debieron adquirir la posesión de sus propias tierras al Gobierno ${ }^{11}$, como forma de asegurar cinco hectáreas para cada campesino frente a los propietarios que insistían en aumentar sus terrenos de labor. Una vez fraccionada la tierra y cuando pretendieron ser dotados de una mayor cantidad, el Comité Ejecutivo Agrario de Tapilula se dio cuenta de que los Títulos Primordiales, que tras la revolución mexicana ampararon a las comunidades con tierras históricamente reconocidas y en posesión, fueron recogidos por el gobierno del estado cuando se efectuó la división territorial. De esta forma, la única manera de conseguir sus objetivos y frenar a los propietarios era recurrir a la Resolución Presidencial y a la expansión a tierras ya ocupadas por distintas fincas.

La reacción de los propietarios no se hizo esperar: un grupo de más de 20 firmantes "todos mayores de edad, casados, agricultores, naturales y vecinos de este pueblo", no creía que existiera razón para la ampliación ${ }^{12}$, principalmente porque "resultaríamos grandemente perjudicados por ser poseedores de pequeñas parcelas agrícolas" y debían derribar sus cafetales y árboles frutales. Su precaria situación económica ("pues todos somos de notoria pobrezan) y la necesidad de mantener sus tierras por el propio bien del estado (pues "dejaría de percibir las contribuciones que nosotros pagamos") afianzaron el discurso de los propietarios para evitar una ampliación de las tierras comunales del municipio.

Uno de los constantes reclamos durante el presente siglo ha sido la necesidad de tierras que paliara la obligación de vender "a bajo precio nuestro trabajo y a descuidar la educación de nuestros hijos" ${ }^{13}$. Igualmen-

11 La compra no implicaba propiedad, sino la traslación del dominio, "con todas las servidumbres y derechos que legalmente les pertenese. De los cuatro compradores tres eran originarios de Tapilula, mientras el cuarto lo era de Copainalá. Destaca de los mismos su relativa juventud, si tomamos en cuenta que la gerontocracia ha sido uno de los temas recurrentes para hablar de la representación política de los zoques: “los señores Rafael y Fermín Morales, José García y Juan Cruz Morales, el primero como de treinta y tres años de edad, el segundo como de cuarenta, el tercero como de veinticinco y el último como de cuarenta y cinco", AECAM, ibid.

12 "No desconocemos la conveniencia que hay en todos los pueblos del ensanche de sus ejidos y Fundo Legal, pero esto es lógico que debe hacerse cuando se avecine la necesidad por razón del aumento progresivo de sus habitantes, lo que indudablemente tiene que suceder en este pueblo, pero será de aquí a largos años y no hoy", AECAM, Exp. 450, 8 de junio de 1933, carta dirigida al gobernador Victorico R. Grajales.

13 AECAM, exp. 450, 18 de abril de 1939, carta del Presidente del Comité Ejecutivo Agrario de Tapilula (Miguel Sánchez) al Presidente de la Comisión Agraria Mixta del Estado. 
te, gracias a la mediación de un representante de la Liga de Comunidades Agrarias y Sindicatos Campesinos del Estado de Chiapas ${ }^{14}$, harán saber a las instituciones agrarias la existencia de "más de 400 campesinos que carecen de tierras para trabajar [además de llevar] muchos años en que están haciendo sus gestiones a este respecto" ${ }^{15}$. Sin embargo, las reclamaciones agrarias y las confrontaciones administrativas no tuvieron una solución hasta que en 1988 se confirmó la posesión comunal de los campesinos ${ }^{16}$. Pese a ello, esta confirmación dejaba sin tierras a un buen número de vecinos y a sus descendientes debido a la imposibilidad legal de ampliarlas.

Maíz, frijol, plátano y caña de azúcar eran los productos básicos cultivados en Tapilula durante el siglo XIX, pero el asentamiento de propietarios en el municipio hizo que el café ganara paulatinamente peso específico; hasta tal punto que durante todo el siglo $\mathrm{xx}$, e incluso en la actualidad, ha formado parte de la economía regional de los comuneros. Este y otros cambios eran detectados a mediados de siglo por Moisés $\mathrm{T}$. de la Peña (1951: 173-174), al señalar a Chicoasén, Copainalá y Tapilula como los únicos pueblos de la Sierra de Pantepec "con apariencias de centro urbano" y "donde hay algo de comercio". Observó también la preponderancia del café en Tapilula que, a pesar de su aislamiento geográfico, se veía arrastrado junto con otros municipios zoques (Tecpatán) “a la moderna vida comercial (ibid.: 307). Así, a mediados del siglo Xx, pudo observar plantaciones de caña y la todavía importante presencia del café, aunque apuntara la existencia de aladeras propicias para la agricultura y para potreros ganaderos" (ibid.: 174).

La consolidación de los propietarios y políticas gubernamentales tendentes a facilitar la expansión ganadera han modificado, desde la década

14 En 1938, la Confederación Campesina se convirtió en Liga de Comunidades Agrarias y Sindicatos del estado para unirse a la Confederación Nacional Campesina (CNC), la cual sustituyó, en palabras de Benjamin (1995: 226), "al gobierno del estado como canal primordial de comunicación entre las organizaciones campesinas y los gobiernos nacionales y estatales".

15 AECAM, exp. 450, 5 de marzo de 1951, oficio dirigido al Presidente de la Comisión Agraria Mixta.

16 La resolución positiva del Cuerpo Consultivo Agrario el 4 de febrero de 1988 abría la puerta para obtener la titulación de las tierras en forma de resolución presidencial, emitida también en forma positiva el 3 de mayo del siguiente año y confirmada con su publicación en el Diario Oficial de la Federación el día 29 de mayo de 1989. 1,352-23-34.56 hectáreas era la superficie reconocida, aunque sólo pudo ejecutarse parcialmente por existir amparos interpuestos de propietarios que veían afectados parte de sus terrenos. Por lo tanto, la superficie entregada fue de 1,328-47-34.56 hectáreas. 
de los setenta, el perfil económico del campo en Tapilula. Si los campesinos poseedores de tierras comunales siguen cultivando los productos básicos (maíz, frijol y plátano) y el café, los propietarios dedican sus tierras a la ganadería extensiva, rubro económico que se ha convertido en el medio principal para la acumulación de capital. Estos cambios en la propiedad de la tierra y en la economía regional pueden confirmarse a través de los datos provenientes del registro civil de Tapilula, que muestran la importancia de la inmigración y su peso porcentual. Lo más significativo es la presencia de pobladores provenientes de los municipios aledaños, concretamente de Rayón, Ixhuatán y Pantepec, por una parte, y de inmigrantes de otras regiones del estado, donde sobresalen los procedentes de San Cristóbal de Las Casas y de comunidades de los Altos. Un seguimiento de algunos de los padres de hijos nacidos en Tapilula después de 1902 muestra cómo un buen número de inmigrantes de los pueblos aledaños y de la zona de los Altos de Chiapas trabajaban en fincas. Además de los propietarios y de los peones de las fincas, debemos añadir la llegada de comerciantes originarios de San Cristóbal y de otros estados de México, aunque aparecen también extranjeros, como es el caso de José Rachid Bitar, procedente de Turquía y que registra en 1916 un hijo con Carolina Rico, natural de Tapilula. Del mismo modo se establecen pobladores foráneos al municipio para desempeñar las tareas burocráticas que el incipiente Ayuntamiento Constitucional requería. Es decir, un seguimiento porcentual indica cómo la presencia de pobladores de otras regiones del estado de Chiapas fue decisiva para la conformación poblacional del actual municipio de Tapilula, destacando su papel en el comercio y en los servicios, mientras los inmigrantes de los municipios aledaños se incorporan en un principio a las fincas y, posteriormente, a las tierras comunales y el peonaje. Por sólo citar un ejemplo, en 1920 los miembros de la Junta Católica de Tapilula solicitaron al provisor de la Sagrada Mitra que les enviara un sacerdote para poder celebrar la fiesta del patrón San Bernardo Abad, por no contar con ningún cura en la parroquia ${ }^{17}$; de los seis firmantes de la carta, al menos tres eran de San Cristóbal, y otro era originario de Tuxtla, la actual capital de Chiapas.

La experiencia migratoria y el discurso sobre la misma tienen, como en otros aspectos de la vida tapilulteca, un marcado carácter ambiguo. Por una parte, aquel que asienta la imposibilidad de los foráneos de comprender al pueblo: "todo el que es nativo sabe cómo su comunidad ha ido andando pero el que es de fuera qué va a saber" (J. G., 23-VI-95),

17 AHD, Asuntos Parroquiales IV, D. 2, Tapilula, 7 de agosto de 1920, feligreses suplican al Provisor de la Sagrada Mitra el envio de un sacerdote. 
mientras que, por otro lado, la misma persona puede enorgullecerse del desarrollo de su municipio en comparación con el vecino: "....ahora es que quieren alcanzarnos, pero el pueblito [Ixhuatán] no ha tenido mucha ampliación, no como acá que se ha ampliado bastante" (J. G., 3-V-96). Esta ambigua dicotomía entre población originaria del lugar y descendientes de inmigrantes es similar a la que se aplica desde el exterior para dividir a la población entre indígena y mestiza, o desde el interior para asentar la separación entre pobres y ricos.

Lo mismo podríamos decir de la percepción que los habitantes del municipio tienen de su composición o perfil étnico. En una encuesta efectuada en un centro educativo a personas que oscilaban entre los 12 y los 49 años de edad, es perceptible esta ambigüedad. El porcentaje más elevado de los encuestados, un $38 \%$, creía que Tapilula era un municipio mestizo; sin embargo el grupo siguiente es el marcado por aquellos que no saben, con un $36,5 \%$, y con un $12,6 \%$ se encuentran aquellos que lo consideran indio y ladino.

Si nos remitimos a lo expuesto en trabajos antropológicos sobre los zoques, podemos encontrar un hilo conductor, y éste no es otro que el que lleva hacia la identidad étnica zoque, cualquiera que sea la temática estudiada. Ciertas prácticas culturales y el idioma fundamentan estas afirmaciones, que provocan un verdadero dilema epistemológico y, por qué no, metodológico, al hablar de la etnicidad. Si la identidad étnica se encuentra en la "superestructura recóndita de su cultura" (Velasco 1991: 254), en los "valores patrimoniales" (Báez-Jorge 1983: 384), o en las prácticas religiosas, nos estamos remitiendo a una esencia cultural en la que importarían poco los cambios históricos, porque serían subsumidos o reinterpretados, y donde lo zoque parecería prolongarse en el tiempo como una mónada. Esto se expresa en fiestas, prácticas religiosas y organización social para dar como resultado, en este silogismo más bien determinista porque parte de una premisa inamovible, la continuidad identitaria zoque.

Si nuestro razonamiento no es el equivocado, o el menos errado dentro del enredo étnico chiapaneco, la premisa tiene como sustento una clasificación tan colonial como la misma categoría de "indio" aplicada por los colonizadores castellanos (Bonfil 1972). Es decir, si la identidad étnica sólo es perceptible y constatable en aquellos individuos unidos a supuestas prácticas culturales tradicionales, no existe la posibilidad de construcción de identidades étnicas a partir de otras premisas o de las mismas premisas (lengua, folklore, organización social...) pero reformuladas; al mismo tiempo que aquellos miembros del supuesto grupo étnico que abandonan la lengua o que organizan su estar en el mundo de forma 
distinta (entiéndase adscripciones religiosas, organizaciones políticas y campesinas...) quedan excluidos de formar parte de ese grupo étnico, o de la posibilidad que ellos mismos tienen de reformularlo o construirlo.

Por este motivo, la identidad étnica parece entenderse en dos direcciones coincidentes: la primera es como consecuente prolongación y parte fundamental de la cultura; la segunda comprende al "grupo étnico" como una unidad cultural-identitaria que procede de un pasado y se prolonga en forma de supervivencia cultural hasta nuestros días, resaltando la etnicidad como un cúmulo de rasgos culturales y simbólicos dispersos pero que pueden unirse en ese comodín supraestructural que parece ser la identidad étnica ${ }^{18}$. El ejemplo de los zoques podría hacerse extensivo a distintas etnias de Mesoamérica y confirmaría la forma arbitraria de servirse, por parte de los antropólogos, de los conceptos étnicos. Con ejemplos obtenidos en Tapilula, apuntaremos elementos para una discusión más abierta.

Es poco frecuente entre los campesinos de Tapilula escuchar referencias a su indianidad; las ocasiones casi siempre están mediadas por la obtención de algo, como el alcohólico que intentaba conseguir comida y lo hacía diciendo que "Somos indígenas campesinos pobres". Por supuesto, este es un caso sesgado, pero intenta ubicarnos en una realidad donde la bandera étnica, al contrario que en otros lugares del actual Chiapas, no tiene un valor único para la acción. Lo que expresaremos con ejemplos es que el recurso étnico en cuanto discurso es sólo eso, un recurso: no contiene un matiz constructor u organizador de un grupo social. Cuestión que no niega, por supuesto, la diferencia cultural, pero que la incluye en una construcción más amplia donde son distintos actores los que participan y de variada manera; actores que no tienen por qué ostentar las mismas ideas siempre y que tienen un interlocutor ambivalente para el intercambio: el Estado y sus instituciones.

El discurso pobres versus ricos es frecuente en el municipio; los campesinos, pero no únicamente, suelen considerar su condición social frente a los ganaderos y comerciantes. En estas ocasiones el indio, el pobre o el campesino afloran para constatar la diferenciación entre tapilultecos acomodados y trabajadores con escasos recursos y poder para capitalizar económicamente su labor diaria. El Presidente de los Bienes Comunales lo expresaba así:

Yo no le hago caso a esa gente; somos distintos; no podemos estar unidos. Como campesino que soy sé que mi carácter no da para que yo me iguale con ellos...

18 Aunque criticado por su labor indigenista, Aguirre Beltrán (1994: 139) sintetiza estas ideas repetidas en la siguiente frase: "La cultura de los pueblos étnicos se transforma sin perder su identidad. 
La gente rica se platica pura cosa grande: ganado, grandes dineros; nosotros platicamos de nuestra pobreza, por eso no pegamos con ellos (M. T., 8-VI-95).

A pesar de estas tajantes aseveraciones, don M. T. ostenta públicamente su compadrazgo con un expresidente municipal y comerciante de Tapilula, además de ayudarlo en tareas de difusión del grupo Alcohólicos Anónimos, prestándole la casa comunal para tal labor. Este ejemplo, como muchos otros, no remite a una identificación social o de clase, trasladable al campo étnico con fronteras nítidas; los mismos campesinos utilizan el discurso contrario frente a los representantes de instancias gubernamentales. En una reunión para tratar sobre los posibles créditos a la producción del café, uno de los campesinos más beligerantes y críticos en las asambleas comunales afirmaba que el Gobierno y sus funcionarios "nos quieren volver indígenas naturales. Con taparrabos y descalzos" (G. M., 9VI-95) ${ }^{19}$. Es decir, el orgullo étnico, relacionado con condiciones sociales de vida, no tiene que estar mediado por la identificación india o étnica como sesgo positivo, sino que puede asumirse como lo que no debe ser. Esto nos habla, más bien, de categorías para la reflexión y la clasificación que no necesariamente se circunscriben a grupos antagónicos, como grupos étnicos o grupos sociales confrontados, sino que conducen a definiciones enredosas y maleables, ambiguas y ambivalentes. No es casual, entonces, que la diferenciación entre ricos y pobres no afecte sólo a los campesinos o indígenas, sino también a personas que ostentan apellidos económica y políticamente relevantes en la región, y que reconocen que no tienen relaciones con sus familiares porque "qué tenemos que hacer nosotros con ellos..., no nos juntamos porque nosotros somos pobres y ellos al saber lo que tienen. Nosotros no tenemos que hacer nada ahí con ellos..." (D. C.,11-VI-95).

Lo que sí podemos asentar como certeza inscrita en los discursos es una clasificación racialista en la región, tanto por parte de los ganaderos como de los campesinos. Por ejemplo, uno de los propietarios decía que en su terreno se habían asentado gente de Rincón Chamula, "chamulitas, porque los de Rayón (zoques) son más civilizados". Estos lugares comunes, que forman parte de cualquier conversación en el estado de Chiapas, se repiten para distinguir a comuneros y propietarios o para insistir en la mejor ubicación, dentro de una supuesta escala evolutiva, de los habitantes de Tapilula porque "aquí la gente es más noble, es tranquilo este

19 La misma persona decía respecto a lo indígena lo siguiente: “La mayoría somos hijos de indios, yo también soy hijo de indio. Viene la civilización y dejamos de hablar zoque, pero la sangre que traemos es de indio, hasta los huesos y no lo debemos desechar, nos debemos sentir orgullosos". 
pueblo". Cuando estas clasificaciones se trasladan de espacio, como por ejemplo a algún país europeo, el contraste vuelve a marcarse al decir que ese "país es civilizado pero aquí hay mucha incivilización, empezando por la indigenada, que les dices quédense aquí dos días y se quedan" (V. C., 3 -VII-95) ${ }^{20}$.

La marca civilizatoria, inscrita en los discursos racialistas, aparece también en el caso del síndico municipal (04-VII-95), quien consideraba el dar educación a sus hijos como un síntoma para que se hicieran "gente de provecho; si no, hubieran sido peones en las fincas o albañiles". Esta percepción es compartida por representantes de familias propietarias; un expresidente municipal ponía en boca de su padre una clasificación similar:

no todos podemos ser iguales, porque hay un cielo y una tierra, pero por lo menos que todos tengamos que comer [...] Mi padre también me enseñó que el libro y el camino hacen al hombre ladino, y por eso he procurado que en Tapilula no se cerraran las escuelas (S. L. B., 17-I-96).

Esta percepción evolutiva y diferencial de lo social a través de la cultura es recurrente. No es casual que otro expresidente municipal, y miembro de una de las familias pudientes del municipio, definiera así la diferencia entre un indígena y aquel que no lo es:

La persona que tiene escuela, roce social, tiene su criterio más bien formado. El indígena se deja guiar por otros porque no tiene criterio, si uno le dice vamos a matar a aquel va y lo hace sin pensar las consecuencias. La gente ladina, digamos, tiene más criterio, ni el Gobierno puede con los de San Juan Chamula, ellos tienen sus autoridades.

Un profesional liberal avecindado en Tapilula, pero originario de otro estado de México, logra definir con claridad ese cúmulo de elementos raciales que conforman la heteropercepción y, en muchas ocasiones, la autopercepción étnica:

La distinción entre nosotros es en el dialecto; los auténticos indígenas hablan el zoque, pero ya casi nadie lo habla. [...] La lengua y la fisonomía nos hace distintos. Los indios son más robustos, cara no ovalada, tampoco cuadrada; no tienen los rasgos del mestizo. Son más bajos, de mediana estatura para abajo. [...] Muy ingeniosos, cualquier cosa se la imaginan. Por ejemplo, Dios es así, en la forma de algo.

20 La respuesta de V. C. se modificó sustancialmente en otra plática, para él "Todos somos mestizos en Tapilula, ya hubo una reestructuración en lo que respecta a mezclas. Ya hay una refinación en la raza, todos hablan el español perfectamente bien". 
Pero los mismos campesinos o miembros del sistema de cargos religiosos de Tapilula no sólo establecen diferencias al interior de la cabecera municipal con los "ricos", también ellos pueden adoptar actitudes de superioridad civilizatoria cuando interactúan con otros sujetos. Un grupo de prioras, por ejemplo, comentando el matrimonio de la hermana de una de ellas, en Rincón Chamula, con un rinconero, bromeaban sobre el enlace con un "chamulita" (tzotzil); otro caso es el de uno de los participantes en el tradicional sistema de cargos quien, cansado de las molestias de los niños, les espetó "...dichosos chamacos, no oyen, parecen indios".

Esta especie de clasificación en orden a superioridades raciales, rituales, laborales, etc., también es frecuente sabiendo que el antropólogo es extranjero. Lo ajeno al espacio de vida puede fácilmente ser superior a lo propio. Tal circunstancia no se limita a los campesinos comuneros, o a los miembros del sistema de cargos, sino a comerciantes y propietarios. Uno de los mayordomos nos preguntaba sobre el tamaño de las cosas "allá de por donde es usted [...] las gallinas deben ser más grandes y más caras en su tierra [...] es que allá hay más ciencia, por eso es que hacen esos aviones y esas cosas, acá ya ve usted" (J. G., 29-IV-96). Pero la diferenciación entre los campesinos y los propietarios tiene puntos de inflexión o de unión cuando lo que se establecen son comparaciones con el exterior. La perspectiva evolutiva o un nivel civilizatorio deficiente comparado con otros es similar: "en España en el año 1967 (?) ya se estaban implementando cosas que aquí anunció ayer el Presidente Zedillo; llevamos 30 años de atraso - afirmaba un propietario-.

Vemos cómo tanto el mayordomo, del sistema de cargos, como el propietario hacen la misma reflexión con respecto a lo que ocurre en países europeos. De esta manera, lo que se plantea con estos ejemplos es que el discurso diferenciador, en muchos sentidos, está construido en el pensamiento de "la plaza pública" (Geertz 1989: 299-338): allí donde es difícil distinguir a indios y ladinos, a campesinos y propietarios, en la forma e intensidad de construir un discurso civilizatorio. ¿Qué se pretende decir con ello? No tanto que no se establezcan diferenciaciones entre unos y otros - y algunos ejemplos ya han sido anotados-, sino que los mecanismos y la estructura de dicha diferenciación no son tan distintos entre estos supuestos grupos antagónicos ${ }^{21}$. Posiblemente, la construcción his-

21 Algo similar es expuesto por María Cátedra (1989: 43-44) cuando establece las diferencias que se generan en el discurso entre los "vaqueiros de alzada" y los "aldeanos" en Asturias. Las diferencias son de grado, puesto que los defectos atribuidos a los vaqueiros son iguales a los que creen poseer los aldeanos: "no son 'desconfiaos', 'falsos', o 'atrasaos', sino 'más' desconfiaos, 'más' falsos, 'más' atrasados que el aldeano, el cual lo es también en menor grado". 
tórica regional, solamente apuntada aquí, donde la conservación de las tierras comunales de labor dejó el trabajo en las fincas a los campesinos migrantes que se incorporaban al municipio, facilitó un mayor intercambio - aunque no siempre en forma de dones- entre comuneros zoques y propietarios. Este hecho, aunado a la progresiva pérdida del idioma zoque, no solapa las relaciones patrón-cliente perceptibles todavía, pero ha posibilitado que los intercambios sean menos dolorosos que los existentes en otras regiones, como es el caso de los Altos de Chiapas. La diferenciación racialista apuntada estaría más en el orden del discurso, porque el hecho fundamental parece ser civilizatorio, es decir, la cuestión racial tiende a subsumirse cuando se inserta en un progreso social y cultural compartido, como lo intuyeron Colby y Van der Berghe (1980) hace varias décadas para el caso de los Altos de Chiapas ${ }^{22}$.

¿Qué nos explican los ejemplos hasta ahora presentados? Nos remiten a diferenciaciones sociales asumidas en prácticas, que no tienen por qué dividirse entre ladinas o indígenas, ya que si esto fuera así ccómo podría entenderse la clasificación que los zoques hacen de los "chamulitas", y su posición de superioridad cuando dan trabajo a jornaleros tzotziles que llegan generalmente para la recolección del café? Más bien estamos hablando de esquemas de diferenciación muchas veces compartidos y, por qué no, coincidentes, que pueden aplicarse en situaciones o espacios distintos. En ciertos momentos, como es el caso de la identificación residencial frente a otros municipios, forman parte del mismo punto de referencia para todos los habitantes del municipio (Tapilula); mientras que en situaciones de interacción con instituciones estatales, los campesinos pueden ser indígenas zoques tanto como huir de dicha clasificación.

El problema radica entonces en definir a ese "otro", sujeto antropológico, desde una mirada abarcadora por supuestamente comprensible, aunque ello signifique dejar de lado las paradojas y elipsis que la misma cultura conlleva. Los sujetos clasificados o agrupados étnicamente por la lengua, por ejemplo, no constituyen necesariamente una unidad política, ni tienen la misma historia, más bien son parte de una cierta "ideología de la etnicidad" que parece más evidente para los foráneos que para los propios interesados, especialmente porque se tienen en cuenta concepciones naturalistas que agrupan a los clasificados bajo una misma comunidad de origen (Pouillon 1993: 114-120).

Esto nos remite, en el debate actual sobre las autonomías étnicas en México, a la aporía que Galinier (1998) señalaba con respecto a los dere-

22 Para adentrarnos en lo problemático de las relaciones y definiciones étnicas en los Altos de Chiapas ver Pitarch (1995). 
chos culturales indígenas. En primer lugar, porque los hablantes de lengua indígena y partícipes de esa diferencia cultural, perceptible fundamentalmente si nos adentramos en el mundo de la cosmovisión, no suelen ser los que reivindican su etnicidad; más bien son aquellos que ya han dejado de hablar el idioma o que no lo transmiten a sus hijos como lengua materna, los que están jugando bazas políticas y de estatus con referentes del mundo tradicional indígena. $\mathrm{Y}$, en segundo lugar, nos conduce a repensar cómo esa diferencia cultural cierta, pero que no es vivida como un proyecto conjunto de comunidades de sangre e historia, se inserta en proyectos que construyen sus propuestas indianistas a través de marcos políticos y jurídicos provenientes de la denostada y etnocéntrica cultura occidental. Posiblemente, la unidad expuesta por los antropólogos, o por el mismo Estado para los grupos étnicos, no interese a los sujetos etnizados porque participan de una organización que reinventa la heterogeneidad, o la lleva consigo, como lo expresa Pitarch (1996) para el caso de los tzeltales de Cancuc (Chiapas).

El ejemplo de Tapilula, como el de muchos otros lugares de Chiapas, nos coloca ante problemas que trascienden el carácter étnico para situarse en la misma construcción de lo social y del ejercicio del poder. Así, se observa la tenaz persistencia de las diferencias entre castas pero ubicada en un debate de grado civilizatorio: debate que, a la vez que sienta las bases para legitimar la jerarquización y desigualdad en el interior de una sociedad, permite también que todos sus miembros participen del mismo. Estas ideas sitúan las expresiones zoques en Tapilula, no como un núcleo cerrado o reflejo de una cultura ajena y aislada del medio social en que se desarrolla, sino como parte de una negociación identitaria plagada de trampas y enredos. Seguramente la reconstrucción histórica de muchos de los municipios con pasado o presente indígena aportaría luz a los procesos políticos que en la actualidad tienen a la etnicidad como el principal motor de las reivindicaciones en México.

\section{ABREVIATURAS}

AECAM: Archivo Estatal de la Comisión Agraria Mixta. Tuxtla Gutiérrez.

AHD: Archivo Histórico Diocesano. San Cristóbal de Las Casas

AHE: Archivo Histórico del Estado. Tuxtla Gutiérrez

ARC: Archivo del Registro Civil. Tapilula 


\section{BIBLIOGRAFÍA CITADA}

Aguirre Beltrán, Gonzalo. 1994. El pensar y el quehacer antropológico en México. México: Universidad Autónoma de Puebla.

BÁEZ-JORGE, FÉLIX. 1983. "La cosmovisión de los zoques de Chiapas (reflexiones sobre su pasado y su presente)", en Antropologia e bistoria de los mixes-zoques y mayas (bomenaje a Frans Blom): 383-412. México: UNAM.

Benjamin, Thomas Louis. 1995. Chiapas. Tierra rica, pueblo pobre. Historia política y social. México: Grijalbo.

Bonfil Batalla, Guillermo. 1972. "El concepto de indio en América: una categoría de la situación colonial. Anales de Antropología IX: 105-124.

CÁtedra, MARía. 1989. La vida y el mundo de los vaqueiros de alzada. Madrid: CISSiglo XXI.

Colby, Benjamin N. y Pierre L. van Der Bergue. 1980. "Relaciones étnicas en el sureste de México", en Evon Z. Vogt (ed.), Los Zinacantecos: 29-62. México: INI (1. ${ }^{2}$ reimpresión).

DE la PENAa, MoIsés T. 1951. Chiapas económico. Tuxtla Gutiérrez: Gobierno del estado de Chiapas.

GALINIER, JACQUES. 1998. "Des 'droits culturels' pour les indiens? Discussion autour d'une aporie ethnographique.. Ponencia en Coloquio Identités, Droits Culturels et Pouvoir. Rencontre Tripartite D'Anthropologues Mexicanistes, Paris.

GEERTZ, ClifFord. 1989. La interpretación de las culturas. México: Gedisa.

PITARCH, PEDRO. 1995. "Un lugar difícil: estereotipos étnicos y juegos de poder en los Altos de Chiapas", en J. P. Viqueira y M. H. Ruz (eds.), Chiapas. Los rumbos de otra bistoria: 237-250. México: UNAM.

- 1996. Cb'ulel: una etnografía de las almas tzeltales. México: FCE.

Poullon, JeAn. 1993. Le cru et le su. Paris: Seuil.

Velasco TORO, JosÉ M. 1991. "Territorialidad e identidad histórica en los zoques de Chiapas". La Palabra y el Hombre 80: 231-258.

Villa Rojas, A.; José M. Velasco Toro; F. Báez-Jorge; F. Córdoba Olivares y Norman D. THOMAs. 1990. Los zoques de Chiapas. México: CNCA-INI (1975).

WASSERSTROM, ROBERT. 1992. Clase y sociedad en el centro de Chiapas. México: FCE. 